\title{
Observations on Brewster's neutral point
}

\section{MM.J.L. Soret \& C. Soret}

To cite this article: MM.J.L. Soret \& C. Soret (1888) Observations on Brewster's neutral point, Philosophical Magazine Series 5, 26:163, 542-543, DOI: 10.1080/14786448808628309

To link to this article: http://dx.doi.org/10.1080/14786448808628309

册 Published online: 29 Apr 2009.

Submit your article to this journal $\widetilde{ }$

Џ Article views: 3

Q View related articles $₫$ 


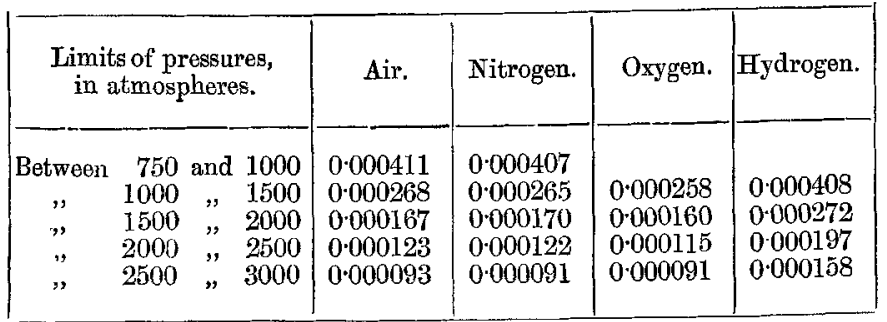

It will thus be seen that at very high pressures oxygen, nitrogen, and air have almost the same compressibility; it is of the same order of magnitude as that of liquids ; at 3000 atm., it is virtually equal to that of alcohol under the normal pressure.

The compressibility of hydrogen is far greater, almost double; at 3000 atm., it is almost equal to that of ether towards the normal pressure.

It is easy to foresee that these compressibilities, like those of liquids, should increase with the temperature; that is shown by the following table with respect to hydrogen.

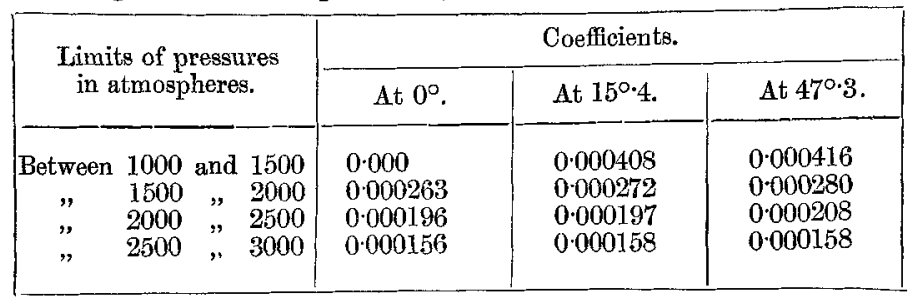

The apparent densities are easily deduced from the former table ; assuming provisionally the number generally adopted for the compressibility of glass, the following results are obtained at $3000 \mathrm{~atm}$.

Densities at 3000 atm. compared with water.

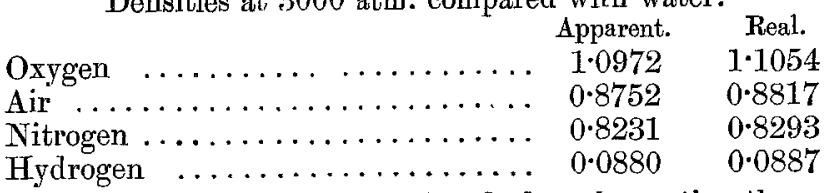

The curves obtained, as I have already done, by putting the pressures on the axis of the abscissa, and the products $p v$ on that of the ordinates, are nearly straight lines, but presenting all a slight concavity turned towards the axis of the abscissæ; I shall return to this important point in reference to limiting volumes, when I have determined the alteration in volume of the envelopes.-Compte rendus, Sept. 17, 1888.

OBSERVATIONS ON BREWSTER'S NEUTRAL POINT.

BY MM. J. L. SORET AND C. SORET.

The neutral point of atmospheric polarization which is below the sun, and which was discovered by Brewster, has been rarely 
seen and determined, to judge at any rate from the publications on this subject. We have had occasion to observe it on the summit of the Righi (height 1800 metres) on the mornings of September 23 and 24 , the height of the sun over the horizon being from $20^{\circ}$ to $35^{\circ}$.

On the $23 \mathrm{rd}$, from 8 to $9.40 \mathrm{~A}$.MI., in remarkably fine weather, it was easy to observe, by means of a Savart's polariscope, that in the immediate neighbourhood of the sun, above as well as below, the polarization of light was negative ; that is to say, that the plane of polarization was porpendicular to the sun's azimuth. Below the sun the fringes of the polariscope gradualiy diminished in intensity, and disappeared at about $14^{\circ}$ of angular distance; a little lower, inverse fringes were seen, the visibility of which increased to the horizon. In order not to be dazzled we interposed an opaque screen in front of the sun, or we placed ourselves in the shade of the iron column of the balcony.

Next day the sky was less clear; we have, however, been able to repeat our observations.

The angular distance of the neutral point is difficult to measure owing to the feebleness of the polarization. We have taken it by determining by a sextant the beight of the sun above the apparent horizon, formed by distant mountains ; then measuring the distance of the neutral point from the horizon by a special apparatus sufficiently accurate to give angles to within $10^{\prime}$; the middle of the neutral space was sighted, which occupied about $4^{\circ}$.

The 24 th September, by the aid of this latter apparatus, we have also determined simultaneously the distance of the neutral point above the sun (Babinet's neutral point).

The following are the numbers which we have obtained :-

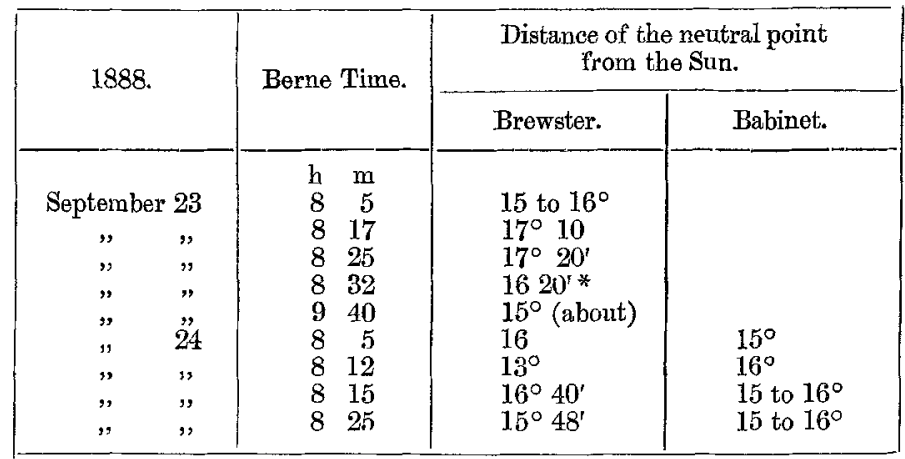

These measurements for the distance of Brewster's neutral point from the sun give very high numbers compared with those which Brewster himself $\uparrow$ and M. F. Busch $\ddagger$ found. Is this a consequence of the altitude at which the observations are made? It would be premature to assert this.-Comptes rendus, October 15, 1888.

* Measured directly with the sextant.

$\dagger$ Transactions of the Royal Society of Edinburgh, vol. xxiii., 1861.

+ Metzorological Zeitschrift for 1886 . 